\title{
Narrativas e experiências acerca da loucura: uma reflexão de profissionais de Comunicação
}

Josenaide Engrácia dos Santos ${ }^{1}$ Cristina Maria Sousa Cardoso ${ }^{2}$

SANTOS, J.E.; CARDOSO, C.M.S. Narratives and experiences about madness: a reflection by communication professionals. Interface - Comunic., Saude, Educ., v.15, n.38, p.727-39, jul./set. 2011.

This study aimed to reflect on narratives and experiences of communication professionals with regard to madness. To understand this experience, we interviewed 14 communication professionals in Salvador: five journalists from four newspapers, five journalists from four television stations and four broadcasters from four radio stations (AM and FM radio). We chose social constructionism as the methodological approach to guide this research because it allows for broader capture of the sense of madness. The views about madness that arose in the narratives took on three dimensions: conceptions of madness; experiences and living with madness; and the relationship between madness and the media. The narratives produced took positions taken from past experience and reflected social practices, such as activity in the media.

Keywords: Narratives. Madness. Communication. Media.
A proposta foi refletir sobre as narrativas e experiências dos profissionais de Comunicação acerca da loucura. Optouse pelo Construcionismo Social como abordagem metodológica da pesquisa por permitir captar o sentido da loucura. Foram entrevistados 14 profissionais de comunicação de Salvador, Bahia, Brasil: cinco jornalistas de quatro jornais; cinco jornalistas de quatro emissoras de televisão, e quatro profissionais de radiodifusão de quatro emissoras de rádio (rádio $A M$ e $F M$ ). As visões sobre a loucura surgidas nas narrativas assumem três dimensões: concepções sobre a loucura; experiências e vivências com a loucura; e relação mídia e loucura. As narrativas produzidas constituem uma tomada de posição diante de uma experiência vivida, a qual interfere nas práticas sociais, como, por exemplo, a atuação na mídia.

Palavras-chave: Narrativas. Loucura. Comunicação. Mídia.

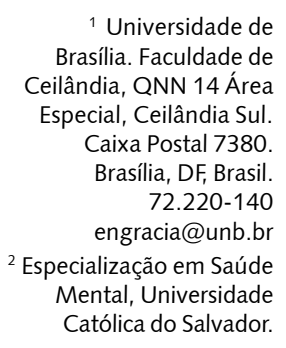

${ }^{1}$ Universidade de Brasília. Faculdade de Ceilândia, QNN 14 Área Caixa Postal 7380.

Brasília, DF, Brasil. 72.220-140 cialização em Saúde Católica do Salvador. 


\section{Introdução}

$\mathrm{Na}$ impossibilidade natural de vivenciar as diversas situações que se manifestam no cotidiano humano, o homem só conhece os fenômenos vividos por seus semelhantes por meio de notícias, sejam essas passadas boca a boca, lidas em revistas, jornais e afins, anunciadas através do rádio ou da televisão, divulgadas por meio da rede mundial de computadores ou de outros veículos voltados para atender a um direito autêntico do ser humano: o da comunicação. E aqui entram o grande valor, poder, influência e efeito social da mídia, por esta constituir um recurso de extremo valor na questão da subjetividade do sujeito e na circulação de conceitos e opiniões. Ela produz sentidos no imaginário popular e mobiliza as pessoas em torno do que veicula.

Tudo o que a mídia difunde carrega em seu âmago uma série de representações associadas a situações passadas. E se as situações já experimentadas coletivamente têm um viés, um contorno culturalmente enraizado, certamente esse viés acompanhará as novas notícias, caso não seja abordada com responsabilidade a evolução pela qual passa ou passou o fenômeno que está sendo noticiado. A partir do publicado, o consumidor dos veículos de comunicação pode decidir se o que está divulgado faz sentido e que espécie de ato se encontra realizado por sua formulação. Para criar consciências críticas, o enunciado deveria não só transmitir conteúdos, mas também atualizar informações anteriores com maior profundidade. Afinal, não seriam também papéis da mídia - além de informar, expor, articular, difundir, revelar e explicar - formar opiniões e aguçar o pensamento crítico da população?

O presente trabalho tem como tema as experiências e narrativas dos profissionais de comunicação sobre a loucura. Para compreender essa experiência, recorremos a relatos que os profissionais de comunicação produziram sobre a loucura. O recurso às narrativas possibilita empreender uma reflexão acerca do contexto em que esta experiência se desenrola e ganha sentido. Apenas quando situamos o profissional de comunicação no quadro da vida é que podemos, realmente, compreendê-lo, captá-lo enquanto parte de um movimento que envolve retomada de descoberta do sentido no curso da própria experiência.

Inquestionável meio de fazer circular repertórios, a mídia tem o poder de criar espaços de interação, propiciando novas configurações aos esforços de produção de sentido. O poder da mídia na figura dos profissionais de comunicação, hoje, alargou-se muito, passando a ser vista como constituidora de sentidos (Lopes, 2006a), ocupando um lugar de referência que traz para si a condição de compor sujeitos, produzir discursos e dar visibilidade a qualquer conteúdo.

Quando se deu o fechamento de três instituições psiquiátricas privadas em Salvador - uma em 2003 e duas em 2006, chegando perto de mil leitos fechados na capital baiana -, a imprensa notificou o fato amplamente na ocasião, afinal, era uma notícia de interesse público e de forte apelo e impacto social. Por conta disso, seria natural que um assunto de tamanha envergadura continuasse sendo pautado, particularmente na mídia impressa, a fim de prover a sociedade dos novos encaminhamentos e caminhos terapêuticos que estavam sendo oportunizados aos portadores de transtornos mentais a partir de então.

Após o tumulto causado pelo fechamento dos hospitais psiquiátricos, a mídia não tem feito mais referência à situação dos portadores de transtorno mental. A sociedade não quer saber? Ou a mídia não se interessa em veicular? E os espaços alternativos, como os Centros de Atenção Psicossocial (CAPS) criados para serem serviços substitutivos do hospital psiquiátrico e para promoverem a construção de uma rede efetiva de cuidados em saúde mental - têm sido convenientemente abordados pela imprensa baiana para orientar a população? E quando alguma divulgação acontece na mídia local, quais os discursos utilizados para tal veiculação? Como os profissionais de comunicação veem a loucura?

E assim o discurso da mídia vai construindo e desconstruindo imagens de identidade coletiva, revelando-se um forte parceiro ou adversário. As imagens coletivas que a mídia constrói são resultado dos discursos que ela elabora, num jogo simbiótico de poder e exclusão que, até hoje, muito pouco tem beneficiado a cidadania dos portadores de transtornos mentais. 


\section{Os métodos da pesquisa}

Optamos pelo Construcionismo Social, como abordagem teórica metodológica para orientar esta pesquisa, porque ele permite captar o sentido da loucura para a mídia tal como ele emerge das falas dos jornalistas e radialistas, não o definindo a priori. Essa abordagem possibilita capturar o processo da produção de sentidos dentro dos contextos sociais, já que se interessa por identificar os repertórios, as formas com as quais as pessoas descrevem sua compreensão e vivência de mundo. Os conteúdos expressos pelo indivíduo, que são essencialmente heterogêneos, traduzem o pensamento, o senso comum de um dado grupo social (Spink, 2003). O Construcionismo Social entende o indivíduo em uma perspectiva social.

O Campo empírico da pesquisa foi in loco, em quatro jornais de Salvador (mídia impressa) $=$ cinco jornalistas; quatro emissoras de televisão (mídia televisiva) = cinco jornalistas; e quatro emissoras de rádio (mídia radiofônica $A M$ e $F M$ ) = quatro radialistas, dando um total de 14 profissionais de comunicação entrevistados.

Os critérios de inclusão foram: ter concluído os cursos que o autorizem a ocupar suas funções; estar na atividade há um tempo mínimo de dois anos; trabalhar em algum veículo da imprensa formal, seja este público ou privado. Os entrevistados foram nomeados de: E1 / E2 / E3 / E4 / E5 / E6 / E7 / E8 / E9 / E10 / E11 / E12 / E13 / E14.

A pesquisa atendeu ao que preconiza a Resolução n 196/96 do Conselho Nacional de Saúde (Brasil, 1996), que regulamenta os aspectos éticos da pesquisa envolvendo seres humanos, e foi autorizada pelo Comitê de Ética em Pesquisa da Universidade Católica do Salvador (UCSaL).

A coleta de dados consistiu em uma entrevista semiestruturada composta de três questões norteadoras. A escolha metodológica mencionada visou a uma busca descritiva, analítica e interpretativa do sentido do indivíduo. O interesse da análise está em compreender como as noções mentalizadas são construídas e usadas na sua relação com os contextos sociais (Spink, 2003).

Para a análise das entrevistas, foi utilizado o mapa de associação, que tem o objetivo de sistematizar o processo de análise das práticas discursivas em busca de aspectos formais da construção linguística, dos repertórios utilizados nessa construção e da dialogia implícita na produção de sentidos (Spink, Lima, 2004). O mapa dá subsídios ao processo de interpretação e facilita a comunicação dos passos subjacentes ao processo interpretativo.

A construção do mapa iniciou-se pela definição de categorias temáticas gerais, baseada na literatura investigada e no objetivo do trabalho. A partir da categorização das respostas, foram organizados os conteúdos, preservando-se a sequência das falas, iniciando-se com categorias gerais. Mesmo sendo iniciado com categorias gerais, o próprio processo de análise pode levar à redefinição das categorias, gerando uma aproximação paulatina com os sentidos (Pinheiro, 2004).

A técnica do mapa de associações de ideias envolveu os seguintes passos:

a) utilizou-se um processador de dados tipo word for windows e digitou-se toda a entrevista; b) construiu-se uma tabela com números de colunas correspondentes às categorias utilizadas; e c) usou-se as funções cortar e colar para transferir o conteúdo do texto para as colunas, respeitando-se a sequência do diálogo. (Spink, Lima, 2004, p.107-8)

Obteve-se, como resultado, um efeito escada, ou seja, a fala dos entrevistados foi gravada, posteriormente transcrita, e, depois, transportada em sua totalidade para mapas de associação de ideias, respeitando a ordem da fala original. Usamos um roteiro que foi dividido em colunas temáticas de associação de ideias. A entrevista dividiu-se em blocos de três colunas. Cada coluna incorporava uma pergunta: como nomeia a loucura, como a descreve e como a explica. A primeira coluna - como nomeia a loucura - serviu de marcador para a introdução dos blocos subsequentes e associativos. $\mathrm{Na}$ 
segunda coluna - como descreve a loucura - foram colocadas as respostas efetuadas a partir da primeira coluna. E a terceira coluna - como explica a loucura -, mais densa, englobou todas as explicações do conteúdo das associações e constituiu uma forma de análise, permitindo compreender o processo da dialogia da pesquisa. Neste ponto temos por foco a discussão dos principais aspectos levantados pelos jornalistas, sobretudo no que concerne às experiências, vivências e representação da mídia.

\section{Resultados - repertório em imagens e vivências}

As visões sobre a loucura surgidas nas narrativas assumem dimensões em três tipos básicos: concepções sobre a loucura; experiências e vivências com a loucura; e relação mídia e loucura.

\section{Concepções sobre a loucura}

No discurso dos jornalistas e radialistas entrevistados, a loucura aparece como um termo extremamente polissêmico, quando percebemos, na linguagem corrente, usos e sentidos dos mais diversos.

Nas narrativas dos entrevistados, a compreensão da loucura bordeja entre alguns universos. Um deles é o universo da clínica médica, ilustrado nos discursos de:

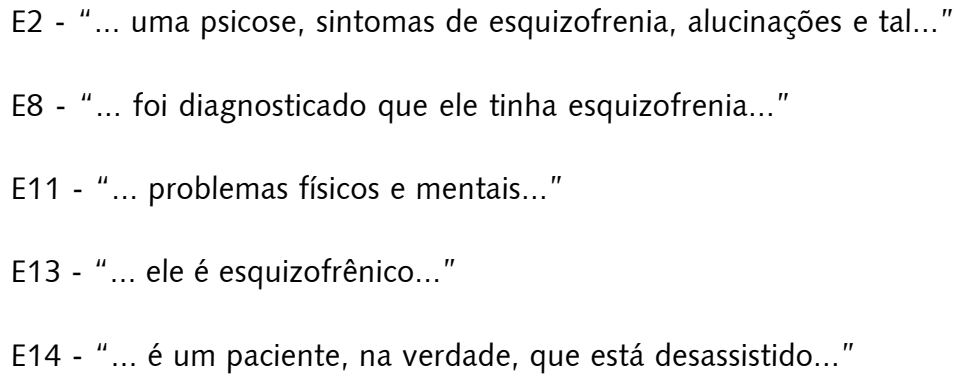

A experiência está fundada no distúrbio como resultado de processos subjetivos, é a percepção científica da loucura pelo saber médico-organicista (Pelbart, 1989):

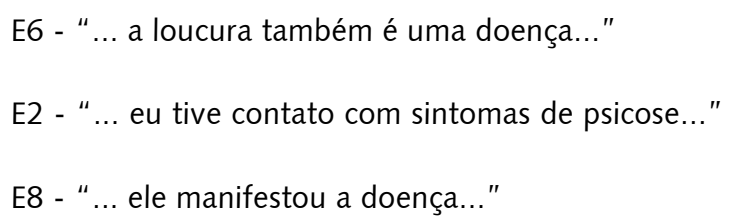

Já em outros discursos, é identificado o universo do medo, onde é descrita a ideia de que o portador de transtorno mental vive em um ritmo diferente. Nesses discursos aparece o louco de comportamento bizarro, estranho. Surge aqui a associação entre o ser maluco e o estar na rua. A associação do maluco ao domínio social da rua é a perda da condição de pessoa, que se reflete em uma crescente negligência, tanto com relação aos outros quanto a si mesmo (Rabelo, Alves, Souza, 1999).

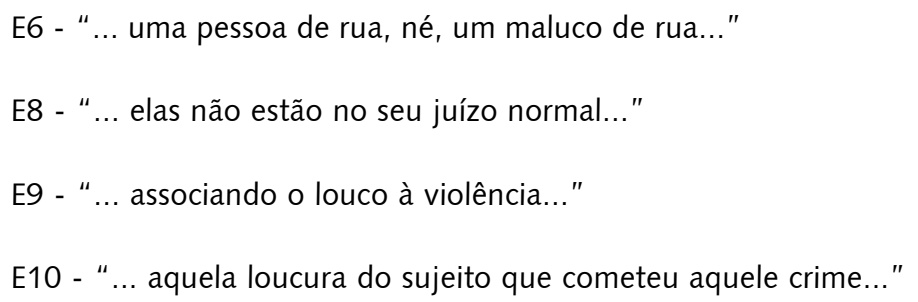


E12 - “... eu comecei a achar mesmo que era loucura, mais pelo comportamento dela, né, assim desequilibrado [...] e tinha uns momentos assim de agressividade..."

E13 - “... comportamento estranho..."

As falas também trazem à tona a loucura socialmente aceita, aquela argumentada pela máxima popular que diz que "de médico e louco cada um tem um pouco", e com a qual muitos dos entrevistados se identificam, até carinhosamente. Nesses momentos, os discursos se revestem de tom cúmplice, afetuoso e ingênuo ao nomearem a loucura. A loucura esteve associada à dimensão do saber que representava uma forma privilegiada de acesso à verdade divina, ou seja, nem sempre a loucura significou doença (Pelbart, 1989).

E10 - “... nessa órbita vivem, transitam, operam várias pessoas, já operaram, né, que tiveram contato com, digamos, com essa situação da loucura, que pode ser também uma situação de extremo prazer, de extrema transportação interna [...] poder dar mais vazão àquela loucura boa que ele tem em si..."

E14 - “... será que o cara não tá um ponto na frente? será que ele não tá um pouco mais à frente, ele não tá vendo o que a gente não enxerga?"

Assim, a loucura pode ser empregada para qualificar algo surpreendente, excepcional, maravilhoso, para designar um ato, fala ou demonstração de alegrias extravagantes que ultrapassem o convencional ou as regras sociais (Houaiss, 2001). Um tipo de experiência subjetiva, algo como perda do autocontrole, da razão ou da consciência de si; um distúrbio ou alteração mental; uma atitude imprudente, insensata; uma paixão desmedida.

A linguagem revela as coisas e lhes dá significados. Os relatos colhidos neste estudo ilustram isso. É, sim, na linguagem que o homem procura articular-se com os vários aspectos do mundo e externaliza o sentido das experiências do seu cotidiano. Desta forma, homem e mundo, em uma condição subjetivoobjetiva, deixam transparecer semelhanças e diversidades entre os seres humanos diante da vivência de realidades similares.

\section{Experiências e vivências com a loucura}

Defrontados com eventos de doença mental, os profissionais de comunicação são convidados a pensar sobre a origem do problema e as ações que passaram a assumir. A grande maioria dos entrevistados descreve algum tipo de experiência com a loucura.

E4 - “... toda rua que se prezava em Salvador tinha seu louco de estimação [...] na minha rua tinha Saborosa, por exemplo, que oscilava ali entre a loucura e o alcoolismo, mas era, vamos dizer, um louco. Ele vivia mesmo à margem, corria atrás da gente, a gente brincava com ele. Mas tinha outros loucos mais perigosos que nos davam susto mesmo, jogavam pedra na gente. Então, era muito comum antes, ali nos anos de 1970, cada rua baiana de Salvador ter seu louco de estimação, né...".

Os casos narrados mesclam descrições dessa experiência e comentários sobre ela.

E2 - “... o meu contato com a loucura, além do contato profissional, de reportagem, de clínica com gente como o próprio doente mental, tenho um contato diário, porque tenho um sogro que - eu não sei nem como é que você está definindo a loucura aí no trabalho mas eu tive contato com sintomas de psicose, né". 
E3, ao contar uma visita que fizera a uma instituição psiquiátrica da cidade, para realizar uma reportagem jornalística, diz:

“... lembro que ali recebi muitas cantadas na ala feminina, acho que pela libido aflorada das pacientes. [...] Uma delas chegou a me atacar... [risos] [...] No final das contas, não consigo definir como foi toda aquela coisa".

Conforme descrita, a experiência parece envolver um forte senso de descompasso entre ator e contexto, oscilando entre uma tensão ou investida constante contra um quadro de eventos e relações cujos detalhes ressaltam como se vistos por lentes de aumento.

Deve-se examinar melhor a noção de experiência. Sem dúvida, uma experiência só é o que é em relação à vida que lhe circunscreve. A experiência funda-se em um senso de pertença e cumplicidade com o mundo, que antecede qualquer elaboração reflexiva sobre objetos, e que nos orienta, abrindo possibilidades de ação (Souza, Rabelo, 2000).

E8 fala da sua experiência e dos conselhos recebidos da mãe, quando criança:

“... a impressão que minha mãe passou pra mim, né, desde a infância, ela sempre falou pra eu ter cuidado na rua quando eu estiver próximo de pessoas que têm problemas mentais, [...] eu sempre procuro não ficar muito próxima das pessoas porque elas não estão no seu juízo normal, elas são pessoas que têm a doença e, a qualquer momento, elas podem surtar e podem agredir quem estiver próximo a elas. Eu tomo esse cuidado...".

Dentro dos relatos das experiências pessoais, temos E9 falando do sofrimento pelo qual sua irmã passou:

“... tenho minha irmã que teve pânico, síndrome de pânico, que não é uma loucura, mas que aí ela foi nesse centro que até achou uma psicóloga...".

A compreensão da loucura não é um objeto que contemplamos de fora, mas um mundo em que estamos envolvidos, com o qual já nos importamos de alguma maneira, é uma realização prática diante do mundo (Souza, Rabelo, 2000). Essa compreensão descrita pode ser ilustrada na fala de E11, quando ele relata uma experiência com um sofredor psíquico que representou muito para ele como ser humano:

E11 - “... já tive experiência com loucura cerca de dez anos atrás, mais ou menos, um pouco mais talvez, quando tive a oportunidade de conviver com um colega que [...] passou por um problema de dificuldade na vida. [...] A experiência veio me mostrar as dificuldades que pessoas que têm esse problema convivem na cidade de Salvador e também no estado da Bahia, [...] pude abrir os olhos no sentido de compreender mais o ser humano, compreender mais as dificuldades, as intempéries que cada um pode passar".

Em toda experiência, o ator reconhece uma situação. O reconhecimento funda-se, é claro, na memória, mas não é simplesmente trazer de novo o passado. Podemos entender que repetir o passado é também reencontrá-lo e aplicá-lo em certo contexto, o que implica tanto conservação quanto criação, ou seja, a experiência não constitui um evento fechado em si mesmo. Assim, ao mesmo tempo em que retoma uma configuração prévia de sentido, a experiência envolve descoberta do sentido em sua aplicação (Gadamer, 1997).

O movimento entre retomada e descoberta, que se desenrola na experiência, diz respeito à sua historicidade, à forma como nela estão implicados passado e futuro.

Entretanto, nem sempre a vivência favorece a quebra do preconceito, como se pode concluir da fala de E8: 
“... e muitas pessoas, até pessoas que eu conheço, elas não deixam tão claro, elas não deixam tão evidente que têm problemas mentais, isso é coisa de família. Eu mesmo, eu não saio por aí dizendo que eu tenho um parente que tem esquizofrenia, entendeu, porque as pessoas começam a olhar pra você de uma forma diferente...".

Alguns entrevistados vivenciaram a loucura no contexto do trabalho:

E13: “... realmente, já tive uma experiência, e foi no meu primeiro emprego, quando eu comecei. E foi uma experiência que me causou certo choque, certa sensação assim de desconforto e me incomodou muito. E me deixou um pouco preocupado com a profissão que eu tava começando [...] E esse colega, ele tinha um comportamento que a gente ficava um pouco preocupado, todos nós na emissora ficávamos preocupados. [...] Depois de seis meses, ele começou a ter um comportamento estranho: conversar sozinho, a agir de uma forma que as pessoas ficaram preocupadas, e aí foi piorando essa coisa de falar só, de agir com um comportamento estranho...".

Nas narrativas colhidas pode-se identificar que o significado das coisas deriva das interações sociais que as pessoas têm com seus companheiros. O que importa não são os sintomas que o indivíduo apresenta, mas a forma como eles são percebidos e categorizados por aqueles que estão ao seu redor (Scheff, Goffman apud Souza, 1999). A experiência com loucura no trabalho produziu um sentido que veio a interferir nas atividades laborais. As práticas discursivas são diferentes maneiras pelas quais as pessoas, por meio dos discursos, ativamente produzem realidades psicológicas e sociais (Pinheiro, 2004).

Assim, os pacientes mentais sofrem não de doença mental, mas de contingências: a visibilidade de suas ações, ou o nível mais ou menos baixo de tolerância da comunidade, status socioeconômico (Souza, 1999). Isso pode ser ilustrado por E13, ao relatar que aquele seu colega portador de transtorno psíquico recebera respostas antagônicas da parte de duas empresas nas quais trabalhou, em momentos diferentes, porém apresentando sintomas semelhantes.

E13 conta da primeira experiência do colega:

"A rádio [...], depois de algum tempo, demitiu esse cidadão".

Em seguida, E13 fala da segunda experiência vivida pelo mesmo colega:

“... Essa mesma pessoa, depois de [...] dez anos depois, ele veio trabalhar aqui [...], e acho que entre seis, oito meses depois ele teve um acesso de loucura [...], não demitiram [...], ele foi internado, fez um tratamento e aconteceu que ele melhorou. Hoje trabalha, [...] hoje realmente ele está uma pessoa normal".

Chegamos a outras narrativas em que a loucura é descrita como signos de sérios distúrbios. As pessoas que tiveram contato mais estreito com algum portador de transtorno mental descrevem a loucura com mais pesar, com menos ingenuidade, com mais realismo, e também fazendo uso de significantes mais voltados ao vocabulário médico e menos ao uso comum. Como diz E11:

“... nada como viver, nada como acompanhar, próximo, de per si, in loco, a situação..."

E10, ao ser perguntado se já tivera alguma experiência com a loucura no seu cotidiano jornalístico, relacionou imediatamente a loucura à periculosidade, ao dizer:

“... Eu, particularmente, não gosto nem de escrever sobre polícia, matérias de editoria de polícia, porque não gosto de me envolver com crimes, com assassinatos, com a violência..." 
O que motivaria essa relação loucura/periculosidade que E10 fez de forma tão automática, tão espontânea? Seria preconceito? Desconhecimento? Falta de interesse? Para alguém que atua na mídia, tal vinculação chama a atenção.

A configuração dos signos relativos à doença mental recai sobre os signos de violência e atitudes agressivas (Rabelo, Alves, Souza, 1999). E8, por exemplo, faz referência a sensações de desconforto, de incômodo: "... eu fico incomodada", diz, várias vezes. E5 e E6 chegam a trazer os significantes "pavor", "medo muito grande" para descrever situações vividas.

A doença, como uma identidade negativa e socialmente estigmatizada, não permite ao indivíduo o retorno à vida normal, como se nada houvesse acontecido. Quando E8 relata sua experiência de diálogo com um funcionário do Hospital de Custódia e Tratamento (HCT), por causa de um interno que teria quebrado um caqueiro em um sítio ecológico, ele não esconde sua indignação ao conferir a discrepância entre crime e pena, manifestando sua solidariedade ao agente de tal ato:

"É, o cara foi lá e surtou, em determinado momento, sei lá, quebrou o caqueiro, é verdade: três anos de cadeia no manicômio judiciário!!!...".

Vemos, portanto, que, se por um lado colhemos repertórios que apontam para sentimentos de medo, indiferença ou preconceito, por outro, identificamos relatos que apontam para sentimentos de compaixão, tolerância, compreensão. Entretanto, isso só está presente nas pessoas que testemunharam a face sofrida da loucura. Nesse particular humano, como em todos os assuntos subjetivos da vida, a experiência faz a diferença.

\section{Relação mídia e loucura}

A loucura parece situar-se entre aqueles conceitos de muito difícil explicação. Todos os entrevistados encontraram dificuldades para expressar sua compreensão a respeito do tema. Entre suspiros e semblantes que sugeriam um não saber, e talvez certo mal-estar provocado pelo inusitado da pergunta, eles tentaram expressar suas opiniões.

E6 parece condensar muitas falas ao confessar:

“... A loucura pra mim ainda é uma incógnita, ainda é uma incógnita...".

A narrativa da identidade é construída com os outros e com os meios de comunicação (Canclini, 1999). E14 diz:

“... que a mídia televisiva não acompanhe, a radiofônica [é] até bem mais restrita, tudo bem, mas acho que a mídia escrita sim, ela tem condição de fazer um trabalho de cobrança, de acompanhamento, mas não faz".

"A palavra é a revelação de um espaço onde os valores fundamentais de uma dada sociedade se explicitam e se confrontam" (Sousa, 1995, p.27). A mídia também expressa seu preconceito. Diz-nos E13:

“... O preconceito faz com que a gente se afaste, não queira nenhum tipo de contato, e até de informação. Eu acho que a mídia, sim, ela tem feito, mas poderia fazer muito mais, né. [...] Tô falando da mídia num âmbito nacional, mas no âmbito local, não. Não tem matérias em jornal falando sobre isso, nem na televisão, nem no próprio rádio não se preocupa em desenvolver algum tema nesse sentido...".

A construção da identidade é indissociável das relações sociais que estabelecemos. E E13 exemplifica isso: 
“... com a experiência que eu tive, a primeira e única experiência com a loucura [...], na época eu estava até achando que tinha alguma coisa a ver com a atividade de radialismo...".

Por meio desse exercício, a identidade pessoal é construída paralelamente à identidade coletiva, uma vez que afirmar seu pertencimento a grupos sociais ou comunidades específicas exige que cada história de vida particular integre de forma ativa a história coletiva (Habermas, 1987). Ou seja, o autor aponta que "as pessoas" preferem justificar seus argumentos e sua opinião com base na ideia preconcebida segundo a qual quando a televisão (ou "a mídia") representa a loucura, o faz apenas com o intuito de denegrir sua imagem, de "piorar as coisas", de passar uma ideia de medo e desassistência.

E9 ilustra muito bem esse ponto de vista:

“... eu acho que a mídia poderia ajudar nesse sentido, no sentido de divulgar, até para as pessoas que têm esses familiares não se sentirem envergonhadas, ou querendo trancar, como se o doente mental provocasse uma vergonha, entendeu? E não é. [...] Todo mundo tá sujeito a isso, entendeu, não tem jeito. E que isso fosse visto de forma mais natural pra que pacientes e familiares sofressem menos. Mas eu não vejo o interesse da mídia em vir antes [do problema]. Depois é que eu vejo os casos na mídia no sentido de crimes, entendeu? Mas no modo geral, não, eu não vejo a mídia [preocupada em esclarecer], nem nos tratamentos...".

Em relação a isso, E2 explica que:

“... a televisão tem uma tendência natural de ser mais superficial, pelo tempo, o assunto entra diluído entre vários outros e tal, então nesse ponto a contribuição acaba não sendo a característica do veículo. Existem programas especiais um pouco maiores que, às vezes, se aprofundam, e acho que cumprem bem isso [...]. Aqui [...] a gente tem [um programa] que vai um pouco além e já tratou do tema, mas no jornalismo diário é sempre muito difícil. [...] Não é fácil abordar isso pela televisão...".

Entretanto, E7 é bem mais enfático ao falar da relação - ou não-relação - entre mídia e loucura:

"A mídia não pensa nada sobre a loucura, a mídia nem liga!!! Você não vê em jornal nenhuma reportagem especial tratando esse tema sério!...".

A partir dessas narrativas, podemos inferir que a mídia é um espaço que pode, sim, reproduzir preconceitos e que trata o tema loucura como sem relevância, ou até sem importância.

Continuando com E9:

“... Eu acho que a mídia se interessa muito mais quando tem um caso de violência. É o que eu observo como alguém que assiste ao jornal, e também como profissional. Eu, pelo menos, na redação e com as pessoas que trabalham em outras redações, é sempre depois de algum crime e de alguma coisa que chame a atenção da opinião pública pela violência, ou porque é parente, e daí as pessoas ficam procurando a causa daquilo. Foi por loucura? Ou sei lá, foi por qualquer outro motivo? [...] Não vejo reportagens que tentem mostrar a situação, assim, de uma forma corriqueira e comum".

Podemos afirmar que as práticas discursivas constituem a linguagem em ação, a forma objetiva pelas quais as pessoas produzem sentidos e relacionam-se no cotidiano (Spink, Medrado, 2004). A partir da perspectiva da produção de sentidos é possível perceber como a mídia foi se formando, uma vez que essa significação é um processo contínuo e histórico.

O significado de que, para a mídia, a loucura não tem valor e não agrega lucro é mencionado pela maioria dos entrevistados, a exemplo de E11: 
"A mídia é comercial, é negócio. E isso, de certa forma, não dá audiência, não dá retorno econômico. Consequentemente, é um lado esquecido. Nós não damos atenção porque a nossa construção é nesse aspecto. A gente precisa de audiência, a audiência é faturamento, a empresa cobra, pede isso - isso todas elas, sem exceção. O rádio e a televisão não têm compromisso com a formação, têm compromisso com a informação, e nem sempre é verdade que ela pode ser aprofundada. Consequentemente, são coisas superficiais".

A alusão que E11 faz à superficialidade com que alguns temas, particularmente os de interesse público, são abordados na mídia reporta-nos ao pensamento de Heberlê e Sapper (2006), quando dizem que os campos sociais se veem tocados pela ação das mídias, mas não podemos ficar esperando da mídia mais que a disseminação contínua dos vários posicionamentos. Isso porque o saber dos jornais é extremamente superficial, mas extenso. Eles se confessam perecíveis; não tratam de fins ou princípios (Lage, 2001). E12, ao falar de sua atuação profissional voltada para a temática da loucura, acaba por ilustrar o dito acima:

“... Eu confesso que na mídia não tenho acompanhado muito como é que está sendo a construção dessa história, mas o que eu já vi, pouco assim, e até de comentários mesmo, é que criaram os Centros de Atenção Psicossocial. [...] Eu não vejo esse acompanhamento em jornal. Eu não vejo isso acontecer. Eu acho que é um caso ou outro, tipo o crime que aconteceu há pouco tempo lá em São Paulo, envolvendo aquele cartunista, então as pessoas começam a pensar nessa questão da loucura. [...] Os jornais têm feito algumas matérias em relação a esse universo da loucura quando eventualmente acontece algum crime. Agora há pouco teve aquele crime lá em Goiás, acho que dos jovens, então, começou-se a questionar se a pessoa tinha condição de sair, ele tinha um problema psiquiátrico, então ele não poderia ter saído da penitenciária. Então eu só vejo um pouco dessa coisa da cobertura da imprensa".

A linguagem cotidiana expressa nos repertórios é fundamental na formação dos sentidos que são compartilhados pela mídia; não a linguagem entendida de forma estática, mas a linguagem posta em movimento no dia-a-dia e que influencia o sujeito.

\section{Discussão}

Entre o sujeito e suas narrativas, há uma relação intrínseca, que não é apenas uma manifestação simbólica dos discursos que circulam socialmente, mas uma expressão simbólica do sujeito em relação ao seu posicionamento no mundo e sua participação social revelada na linguagem. A linguagem é prenhe de sentidos subjetivos, emoções, afetos, entre outros (Ricouer, 1987), a linguagem é o processo pelo qual a experiência privada se faz pública.

Os discursos dos entrevistados, segundo Spink (2004), trazem à tona as ideias com as quais convivemos, as categorias que usamos para expressá-las e os conceitos formalizados a partir de domínios diversos (da religião, arte, filosofia), de grupos que nos são próximos (família, comunidade, vizinhança), e da mídia em geral. É a produção de sentidos caracterizada nos discursos. Para captar o sentido de um discurso é preciso recuperar o contexto dialógico em que ele se situa (Bakhtin, 1981). As práticas discursivas moldam e constituem os fenômenos sociais (Lopes 2006b); consequentemente, as práticas sociais produzem sentidos nos meios midiáticos.

As formas pelas quais os entrevistados ligados à mídia nomeiam, descrevem e opinam sobre a relação mídia-loucura deixam fortes marcas e parecem incorporar que as variações da loucura tratam as diferenças em uma mesma perspectiva: a de encarar a loucura como distúrbio ou periculosidade, sentido que é repassado para a sociedade. O que é comunicado (Ricouer, 1987) é a sua significação, que é a prática discursiva intrínseca à prática social.

Vestida injustamente com a roupagem da violência ou maquiada ingenuamente como sinônimo de liberdade, o fato é que a loucura tem tido uma só realidade, uma só posição no espaço da mídia: a da 
exclusão e negação de sua condição humana merecedora de respeito e dignidade, o que foi retratado pelos profissionais de comunicação entrevistados. Não podemos esquecer que o modo de construção das notícias é povoado de representações (Lopes, 2006b). É o universo da linguagem, onde a ideologia aparece como dimensões construtivas dos discursos e da realidade social.

As narrativas aqui investigadas dos profissionais de comunicação comovem, enfurecem, persuadem, incitam a ação. Assim, contribuem para o reconhecimento das experiências vividas por outros, sobretudo no universo da mídia, campo de interlocução e discussão da realidade social da loucura no mundo da comunicação.

\section{Reflexões finais}

Pensar as narrativas dos profissionais de comunicação como discurso é percebê-las como constituintes de uma prática que se caracteriza não somente por representar o mundo, mas também por significá-lo e construí-lo, sem perder de vista a constituição discursiva da sociedade como prática social. As narrativas sobre a loucura organizam-se ao redor de temas como estigma, preconceito e violência, revelando formas próprias de abordar e lidar com o problema. Os temas põem à mostra o sentido da loucura e as concepções acerca da mesma para os profissionais de comunicação e, consequentemente, da mídia, que parecem compreendê-la como a ruptura de elos que conectavam o indivíduo aos contextos.

Nas narrativas, o sujeito fala sempre de algum lugar, e não fala sozinho. Isto implica compreender que as práticas discursivas moldam e constituem os fenômenos sociais; por conseguinte, as práticas sociais produzem sentidos.

Esta afirmação demanda a compreensão de que as pessoas lidam com práticas concretas na sua existência e no cotidiano. Logo, os discursos não atuam sozinhos, mas estão conjugados a outras práticas sociais, como é o caso dos profissionais de comunicação das várias mídias.

Encontram-se, também, nas narrativas, informações relevantes acerca da maneira ainda estigmatizada e excludente com que a loucura é tratada, reforçando as ideias de periculosidade e segregação com as quais o portador de transtorno mental e a sociedade têm convivido há muito tempo. A loucura é vista como doença e como assunto público; contudo, não circula na mídia. Pior: quando circula, está associada à rejeição e, até mesmo, à violência, o que leva à perpetuação dessa segregação, dessa hostilidade social midiaticamente justificada.

Quanto à circulação de informações pela mídia, podemos dizer que as mesmas contribuem para a estigmatização quanto ao tema loucura. Diante desta premissa, a notícia passa a ser um lugar de construção de sentidos, de sujeitos e de realidade, produzida, reproduzida e transformada nos discursos, ou seja, nas notícias. Violenta, divina ou libertadora, a loucura expressa o modo de convivência dominante nas narrativas, o que repercute na mídia e nas práticas sociais.

\section{Colaboradores}

As autoras Josenaide Engracia dos Santos e Cristina Maria Souza Cardoso participaram, igualmente, da elaboração do artigo, de sua discussão, redação e da revisão do manuscrito. 


\section{Referências}

BAKHTIN, M. Problemas da poética de Dostoiévski. Rio de Janeiro: Forense Universitária, 1981.

BRASIL. Ministério da Saúde. Resolução 196/96, do Conselho Nacional de Saúde/MS. Institui diretrizes e normas regulamentadoras de pesquisa envolvendo seres humanos. Diário Oficial da União, Brasília, DF, n. 201, 16 out. 1996. Seção 1, p.21082-5.

CANCLINI, N.G. Consumidores e cidadãos: conflitos multiculturais da globalização. 4.ed. Rio de Janeiro: Editora UFRJ, 1999.

GADAMER, H.G. Verdade e método 1: traços fundamentais de uma hermenêutica filosófica. Petrópolis: Vozes, 1997.

HABERMAS, J. Teoría de la acción comunicativa I: racionalidad de la acción y racionalización social. Trad. Manuel Jiménez Redondo. 4. ed. Madrid: Taurus, 1987.

HEBERLÊ, A.; SAPPER, S. Mídia, produção de notícias e significação. UNIrevista, v.1, n.3, p.1-11, 2006. Disponível em: <http://www.alaic.net/ponencias/ UNIrev_HeberleSapper.pdf>. Acesso em: 17 maio 2010.

HOUAISS, A. Dicionário da Língua Portuguesa. Rio de Janeiro: Objetiva, 2001.

LAGE, N. Ideologia e técnica da notícia. 3.ed. Florianópolis: Insula, 2001.

LOPES, P.F. Midiologia. In: ENCONTRO NACIONAL DA REDE ALFREDO DE CARVALHO, PORTAL DA ALCAR - ASSOCIAÇÃO BRASILEIRA DE PESQUISADORES DE HISTÓRIA DA MÍDIA, 4., 2006, São Luís. Anais... São Luís: Alcar, 2006a. p.1-14. Disponível em: http://www.intercom.org.br/boletim/a05n142/destaque02.shtml. Acesso em: 17 maio 2010.

A notícia como produtora de sentidos. UNIrevista, v.1, n.3, p.1-9, $2006 \mathrm{~b}$. Disponível em: <http://www.unirevista.unisinos.br/_pdf/UNIrev_Lopes.PDF>. Acesso em: 17 maio 2010.

PELBART, P.P. Da clausura do fora ao fora da clausura: loucura e desrazão. São Paulo: Brasiliense, 1989.

PINHEIRO, O.G. Entrevista: uma prática discursiva. In: SPINK, M.J. (Org.). Práticas discursivas e produção de sentidos no cotidiano: aproximações teóricas e metodológicas. 2.ed. São Paulo: Cortez, 2004. p.183-214.

RABELO, M.; ALVES, P.; SOUZA, I.M. Experiência de doença e narrativa. Rio de Janeiro: Ed. Fiocruz, 1999.

RICOEUR, P. Teoria da interpretação. Lisboa: Ed. Porto, 1987.

SOUZA, I.M. O asilo: perfis do hospital psiquiátrico em narrativas sobre doença mental. In: RABELO, M.; ALVES, P.C.; SOUZA, I.M. (Orgs.). Experiência de doença e narrativa. Rio de Janeiro: Ed. Fiocruz, 1999. p.139-68.

SOUZA, I.M.; RABELO, M.C. Vida vivida, vida contada: uma reflexão sobre a experiência de nervoso na trajetória de mulheres de classe trabalhadora em Salvador. In: ENCONTRO ANUAL DA ANPOCS, 24., 2000, Petrópolis. Programa e Resumos... Petrópolis, 2000. s/p.

SOUZA, J.S. Infância e linguagem: Bakhin, Vigotsky e Benjamin. Campinas: Papirus, 1995.

SPINK, M.J. (Org.). Práticas discursivas e produção de sentidos no cotidiano: aproximações teóricas e metodológicas. 2.ed. São Paulo: Cortez, 2004.

Desvendando as teorias implícitas: uma metodologia de análise das representações sociais. In: GUARESCHI, P.A.; JOVCHELOVITCH, S. (Orgs.). Textos em representações sociais. Petrópolis: Vozes, 2003. p.117-45. 
SPINK, M.J.; LIMA, H. Rigor e visibilidade: a explicitação dos passos da interpretação. In: SPINK, M.J. (Org.). Práticas discursivas e produção de sentidos no cotidiano: aproximações teóricas e metodológicas. 2.ed. São Paulo: Cortez, 2004. p.93-122.

SPINK, M.J.; MEDRADO, B. Produção de sentidos no cotidiano: uma abordagem teórico-metodológica para análise das práticas discursivas. In: SPINK, M.J. (Org.). Práticas discursivas e produção dos sentidos no cotidiano: aproximações teóricas e metodológicas. 2.ed. São Paulo: Cortez, 2004. p.41-61.

SANTOS, J.E.; CARDOSO, C.M.S. Narrativas y experiencias sobre la locura: una reflexión de profesionales de la comunicación. Interface - Comunic., Saude, Educ., v.15, n.38, p.727-39, jul./set. 2011.

Este estudio tiene como objetivo reflexionar sobre las narrativas y experiencias de profesionales de la comunicación sobre la locura. Para entender esta experiencia se realizaron entrevistas con 14 profesionales de comunicación de Salvador, Bahia, Brasil: cinco periodistas de cuatro periódicos; cinco periodistas de cuatro estaciones de televisión y cuatro profesionales de radiodifusión de cuatro emisoras de radio (radio AM y FM). Elegimos el constructivismo social como un enfoque metodológico para guiar esa investigación, ya que permite captar el sentido de la locura. Los puntos de vista sobre la locura que se plantean en los relatos se presentan en tres dimensiones: concepciones sobre la locura; convivio y experiencias con la locura; los medios de comunicación y la locura. Los relatos reflejan una tomada de posición frente a una experiencia vivida, la cual interfiere en las prácticas sociales, por ejemplo, en los medios de comunicación.

Palabras clave: Narrativas. Locura. Comunicación. Médios de comunicación. 